\title{
SEISIMPACT-THES: A SCENARIO EARTHQUAKE AFFECTING THE BUILT ENVIRONMENT OF THE PREFECTURE OF THESSALONIKI
}

\author{
Kiratzi A. ${ }^{1}$, Roumelioti Z. ${ }^{1}$, Benetatos Ch. ${ }^{1}$, Theodulidis N. ${ }^{2}$, Savvaidis A. ${ }^{2}$, Panou A. ${ }^{1}$,
} Tziavos I. N. ${ }^{3}$, Savvaidis P. ${ }^{4}$, Hatzigogos Th. ${ }^{5}$, Koutoupes $S .{ }^{6}$ and Karantonis G. ${ }^{7}$

1 Department of Geophysics, Aristotle University of Thessaloniki, P.O. Box 352-1, 54124, Thessaloniki,Kiratzi@geo.auth.gr, zroum@lemnos.geo.auth.gr, benet@lemnos.geo.auth.gr, apanou@lemnos.geo.auth.gr

2 Institute of Engineering Seismology and Earthquake Engineering, P.O. Box 53, 55102 ntheo@itsak.gr, alekos@itsak.gr

${ }^{3}$ Division of Geodesy and Surveying, Department of Rural and Surveying Engineering, Aristotle University of Thessaloniki, tziavos@olimpia.topo.auth.gr

${ }^{4}$ Laboratory of Geodesy, Division of Geotechnical Engineering, Department of Civil Engineering, Aristotle University of Thessaloniki, psav@civil.auth.gr

${ }^{5}$ Laboratory of Soil Mechanics and Foundations, Division of Geotechnical Engineering, Aristotle University of Thessaloniki, hatz@geo.civil.auth.gr

${ }^{6}$ Hellas On Line (HOL), 59-61 Agiou Konstantinou str, Building B, 15124 Marousi, Athens, skout@hol.net

${ }^{7}$ Agiltech S.A., 18 Aetideon, 15561, Holargos, Athens, gkarant@agiltech.gr

\section{ABSTRACT}

In the framework of the "SEISIMPACT-THES" project (Koutoupes et al., 2004; Savvaidis et al., 2004) a GIS database has been designed to include information on a wide range of components related to seismic risk within the broader area of the prefecture of Thessaloniki. One of these components refers to the distribution of strong ground motion produced by large earthquakes and the ability of a potential future user of the database to retrieve information regarding the distribution of strong ground motion from past destructive earthquakes in the area of Thessaloniki, as well as relative information for realistic future scenario earthquakes in the same area.

The selection of future scenario earthquakes that may affect this urban region of interest is based on a combined review of historical data, previous probabilistic and deterministic hazard assessments, seismotectonic and microseismicity studies, relocated seismicity in northern Greece and the experience gained from worldwide research. In this study we present the results from hypothetical rupture of one fault that is located at the suburbs of the city, the Asvestochori fault. Empirical relations applicable to Greece (Papazachos \& Papazachou 2003), as well as seismicity information are combined to determine the dimensions of the scenario earthquake source. Strong ground motion for the selected scenario is simulated using the stochastic method for finite faults (Beresnev and Atkinson, 1997). Uncertainties due to unknown parameters such as the rupture initiation point and the distribution of slip on the fault plane are taken into account by examining a large number of random scenarios. The average values from these multiple scenarios are then used to compile maps of strong ground motion parameters (e.g. peak ground acceleration and spectral acceleration). Although the examined scenario earthquake is moderate in size (Mw 5.2), the level of the resulting strong ground motion parameters is indicative of the potential destructiveness of the examined source. Due to the simplicity in the underlying assumptions of the stochastic method, the results of this study are a first-order approximation to the problem of defining expected shaking in the wider area of Thessaloniki. Other strong motion simulation methods of more deterministic character will also be applied for the same purpose in the framework of the SEISIMPACT-THES project. 


\section{INTRODUCTION}

Earthquake scenarios describe the expected ground motions and effects of specific hypothetical earthquakes. To simulate a hypothetical earthquake, one needs to make assumptions on the location and the size of the event, although this does not mean that the specific earthquake will indeed occur. Nevertheless, simulations of scenario earthquakes enhance our present knowledge of the potential destructiveness of specific seismic sources and can, therefore, be used for earthquake disaster planning and preparedness purposes.

Contributing to planning and coordination of emergency response to a large earthquake close to urban areas is one of the main targets of the "SEISIMPACT-THES" Project (http://www. seisimpact.gr). This project aims to the development of an advanced Geographic Information System, which will include topographic, geological, seismological and geophysical data, as well as detailed information about damage caused from previous large earthquakes in the area of interest. Furthermore, this system will provide synthetic strong ground motion parameter maps for hypothetical earthquakes.

The SEISIMPACT-THES information system is being designed with an open architecture, so that it will be usable in any area for which sufficient data exist. Nevertheless, its initial form will contain information on the area belonging to the Prefecture of Thessaloniki.

In the frame of this project, we present some first simulation results for an earthquake scenario in the proximity of the city of Thessaloniki. This hypothetical earthquake is related to the Asvestochori fault, which is believed to dip underneath the city (Papazachos et al. 2000)

\section{METHOD}

The method used to assess the expected strong ground motion from scenario earthquakes close to the city of Thessaloniki is the stochastic method for finite sources, which is based on the idea that high-frequency motions can be considered random (Hanks 1979, McGuire \& Hanks 1980, Hanks \& McGuire 1981). Boore (1983) was the first who applied this idea to simulate strong ground motions from point sources and few years later Beresnev \& Atkinson (1997) extended the original method to encompass effects from finite sources. The method of Beresnev \& Atkinson (1997) involves discretization of the fault plane of the simulated earthquake into smaller subfaults, each of which is assigned an $\omega^{2}$ spectrum. Contributions from all subfaults are empirically attenuated to the observation site and appropriately summed to produce the synthetic accelerogram. For a detailed description of the stochastic method, the reader is referred to Boore (2003) and to references therein.

All simulations presented in this study are performed using the finite-fault simulation code FINSIM (Beresnev \& Atkinson, 1998). The applicability of the code to ground motion predictions has been tested and verified by numerous researchers and in various seismotectonic environments (e.g. Hartzell et al. 1999, Castro et al. 2001, Beresnev \& Atkinson 2002, Hough et al. 2003, Roumelioti \& Kiratzi 2002, Singh et al. 2003). This code and the stochastic method in general, have been previously applied in Greece to simulate strong ground motions from past strong earthquakes (Papastamatiou et al. 1993, Margaris \& Papazachos 1994, Margaris \& Hatzidimitirou 1997, Margaris \& Boore 1998, Roumelioti et al. 2000, Roumelioti et al. 2003, Benetatos \& Kiratzi 2004, Roumelioti et al. 2004).

\section{SEISMOTECTONIC SETTING}

Thessaloniki lies in the northern part of the Aegean Sea region, where seismotectonics are controlled by the N-S extension of the back-arc area and the dextral strike-slip motions transferred from the east along western termination of the North Anatolian Fault Zone (NAFZ) into the Aegean (Kiratzi 2002). Inherited structures that dominate the broader area are thrust, reverse and strike-slip faults of the Alpide deformation, whereas normal and oblique-slip faults have also been formed or reactivated by the post-orogenic extension. These latter structures are of different orientations, which vary from NNE-SSW to E-W, although the predominant orientation is NW-SE. The E-W 
trending structures are few and rather small, but presently active as they are oriented perpendicular to the active stress regime.

The broader area of northern Greece is characterized by intense seismic activity, which is basically concentrated along the Serbomacedonian geological zone, to the east of the city of Thessaloniki. This zone consists a permanent threat to the Prefecture of Thessaloniki, although more distant large earthquakes e.g. from the area of Kresna in Bulgaria have also been proven damaging. In figure 1, we show the epicenters of known historical and recent earthquakes (Papazachos \& Papazachou 2003) that have affected the built environment of the city of Thessaloniki. Of particular interest is the earthquake of 1759 , which according to historical macroseismic information (Papazachos \& Papazachou 2003 and references therein) ruined the largest part of the city and caused the death of many people. This earthquake is not clearly related to any of the known fault structures around Thessaloniki, although the extent of the caused damage implies that its epicenter was very close to the city.

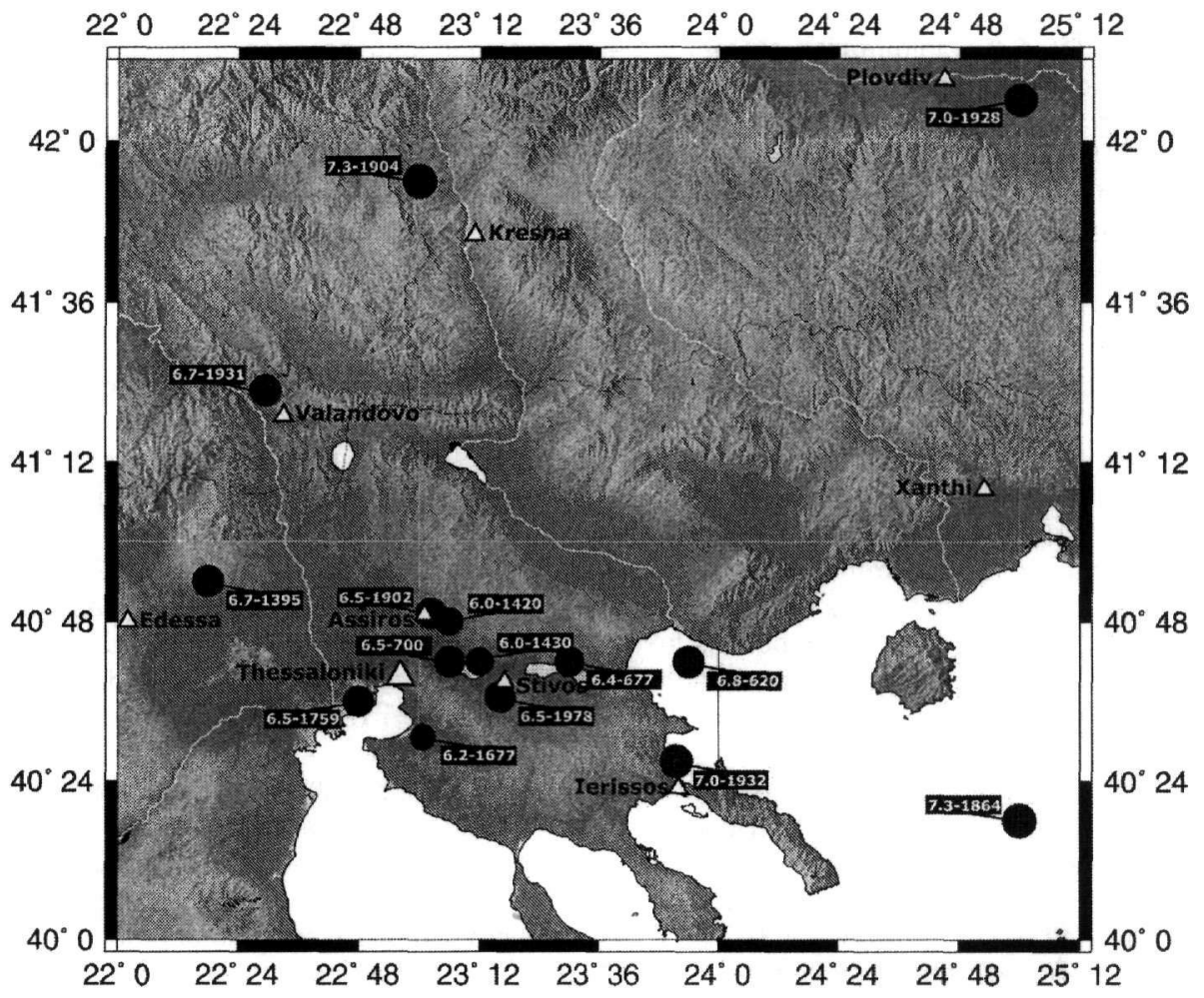

Figure 1. Past large earthquakes that have affected the built environment of Thessaloniki.

\section{APPLICATION OF THE STOCHASTIC METHOD}

\section{I Simulation Parameters}

In the methodology of Beresnev \& Atkinson $(1997,1998)$ modeling of the finite source requires information on the orientation and the dimensions of the fault plane, as well as information on the dimensions of the subfaults and the location of the hypocenter.

The orientation and the dimension of the fault model were chosen based on the spatial distribution of the foci of the 1999 Asvestochori sequence (Papazachos et al. 2000), as well as on geological information (Tranos et al. 2003) and empirical scaling relations applicable to Greece (Papazachos \& Papazachou 2003). 
The discretization of the fault was done using the empirical relation (Beresnev \& Atkinson 1999):

$$
\log \Delta /=0.4 M-2
$$

where $\Delta l$ is the subfault dimension and $M$ the simulated earthquake magnitude.

Another important input parameter of the employed methodology is the "stress parameter" $\Delta \sigma$. Since $\Delta \sigma$ is known with very large uncertainties for past events and even larger for future ones, we decided to keep its value fixed at 50 bars (Kanamori and Anderson, 1975), following the suggestion of the writers of the simulation code used (Beresnev and Atkinson, 1997). After all, a fixed value of this parameter primarily affects the number of elementary sources that need to be summed in order to conserve the seismic moment of the target event and not the radiation amplitudes (Beresnev and Atkinson, 1997).

The propagation model includes parameters for the geometric spreading, the anelastic attenuation and the near-surface attenuation, as well as site amplification factors.

For the geometric attenuation we applied a geometric spreading operator of $1 / R$, while the anelastic attenuation was represented by a mean frequency-dependent quality factor for Aegean and the surrounding area, $Q(f)=100 f^{0.8}$ (P. Hatzidimitriou, personal communication).

The effect of the near-surface attenuation was also taken into account by diminishing the simulated spectra by the factor $\exp (-\pi \mathrm{f} \kappa)$ (Anderson and Hough, 1984). The kappa operator was given the values $0.035,0.044$ and 0.066 for site classes $B, C$ and $D$, respectively (Margaris \& Boore 1998, Klimis et al. 1999).

The material properties are described by density, $\rho$, and shear - wave velocity, $\beta$, which were given the values $2.72 \mathrm{gr} / \mathrm{cm}^{3}$ and $3.4 \mathrm{Km} / \mathrm{sec}$, respectively.

There are three more parameters that we cannot "a priori" determine for an earthquake and these are: the location of the rupture initiation point, the distribution of slip on the fault plane and a parameter called sfact (Beresnev \& Atkinson 1997, 1998), which controls the amplitudes of the radiation at frequencies higher than the corner frequency of the subfaults and has been linked to the maximum velocity of slip on the fault (Beresnev and Atkinson, 1997). Regarding the last parameter, Beresnev \& Atkinson (2001) suggested an average value of $1.5 \pm 0.3$ based on a large number of simulated earthquakes. We examined values within the entire range from 1.2 to 1.8 , using a step of 0.1 ( 7 values in total). Furthermore, we tested all possible rupture initiation points by successively moving the initiation point to a different subfault of the fault model ( 25 locations in total, i.e. equal to the number of subfaults) and performed simulation for 30 random slip distribution models. In total, for each observation point we computed $7 \times 25 \times 30=5,250$ synthetic accelerograms and response spectra.

A summary of the simulation parameters is presented in table 1.

Table 1. Simulation parameters for the $M w=5.2$ scenario earthquake on the Asvestochori fault.

\begin{tabular}{ll}
\hline Parameter & Adopted Value \\
\hline Fault orientation & Strike $140^{\circ}$, Dip $55^{\circ}$ \\
Fault dimensions $(\mathrm{Km})$ & $6 \times 6$ \\
Mainshock moment magnitude $\left(\mathrm{M}_{\mathrm{w}}\right)$ & 5.2 \\
Stress parameter (bars) & 50 \\
Subfault dimensions $(\mathrm{Km})$ & $1.2 \times 1.2$ \\
Subfault moment (dyne-cm) & $1.0 \times 10^{25}$ \\
Number of subfaults & 25 \\
Number of subsources summed & 6 \\
Subfault corner frequency $(\mathrm{Hz})$ & 1.7 \\
Crustal shear-wave velocity $(\mathrm{Km} / \mathrm{sec})$ & 3.4 \\
Crustal density (gr/cm $\left.{ }^{3}\right)$ & 2.72 \\
Distance-dependent duration term $(\mathrm{sec})$ & Duration equal to source rise time \\
Geometric spreading & $1 / \mathrm{R}$ \\
$\mathrm{Q}(\mathrm{f})$ & $100 \times \mathrm{f}^{0.8}$ \\
\hline
\end{tabular}




\subsection{Results}

Synthetic acceleration time histories were computed at grid points covering the area (latitude/longitude): $40.575^{\circ} \mathrm{N} / 22.725^{\circ} \mathrm{E}$ up to $40.775^{\circ} \mathrm{N} / 23.075^{\circ} \mathrm{E}$, using a grid spacing of $0.025^{\circ}$ and assuming hard rock surface conditions throughout the examined area. The 5,250 synthetic waveforms computed for each grid point were then used to estimate the average peak ground acceleration (PGA) and average peak spectral acceleration (PSA) at each point and the resulting values were used to compile the corresponding strong ground motion parameters maps.

The PGA map for the scenario $M w=5.2$ earthquake on the Asvestochori fault is shown in figure 2. The map is contoured in units of $\mathrm{cm} / \mathrm{sec}^{2}$, using a contour interval of $50 \mathrm{~cm} / \mathrm{sec}^{2}$. PGA values within the city of Thessaloniki range from 150 up to more than $300 \mathrm{~cm} / \mathrm{sec}^{2}$ and maximum values are observed, as expected, within the projection of the fault plane.

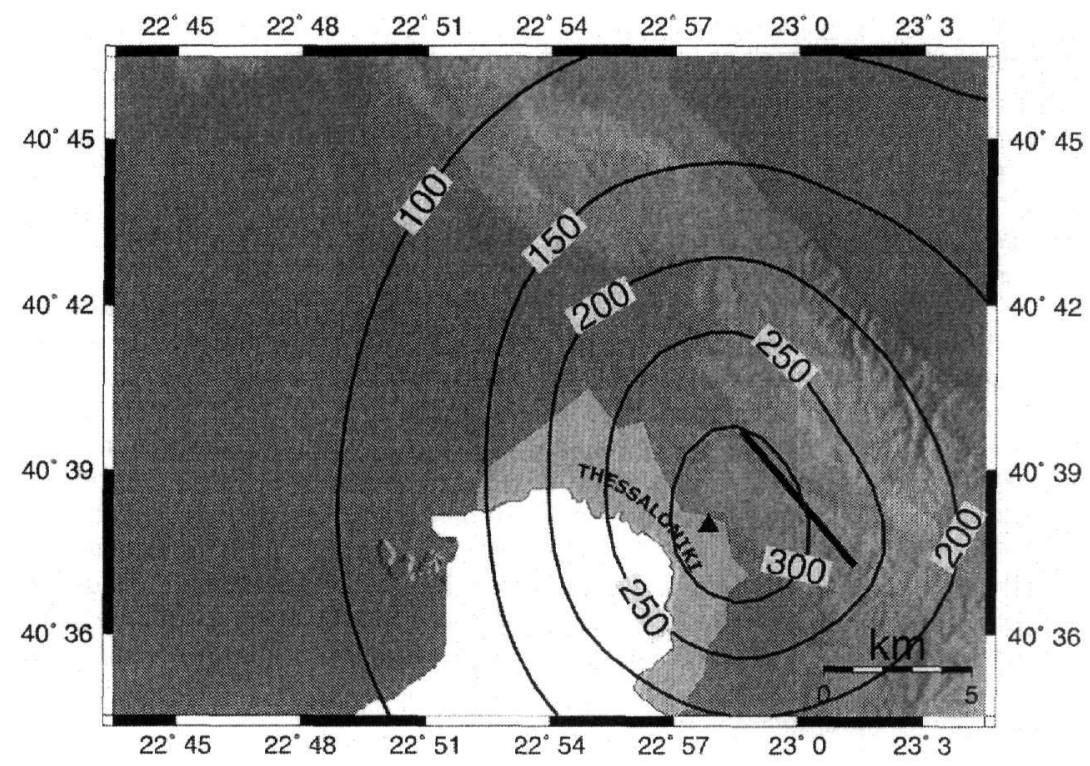

Figure 2. Average PGA map for the scenario earthquake of $M w=5.2$ on the Asvestochori fault. Values are in $\mathrm{cm} / \mathrm{sec}^{2}$ and the contour interval is $50 \mathrm{~cm} / \mathrm{sec}^{2}$. Thick black line corresponds to the surface projection of the upper edge of the adopted fault model.

Response spectra portray the response of a damped, single-degree-of-freedom oscillator to the input ground motions. In figures 3 and 4 , we present response spectra maps for the examined earthquake scenario at two reference periods: 0.2 and $0.65 \mathrm{sec}$, respectively. These period values were chosen because they are close to the average resonance periods of typical building constructions in the city of Thessaloniki ( $0.2 \mathrm{sec}$ for low buildings and $0.65 \mathrm{sec}$ for 6 to 9 storey buildings). For each grid point, the value used is the peak horizontal value of $5 \%$ critically damped pseudoacceleration. PSA values within the city of Thessaloniki range from 0.3 to more than $0.6 \mathrm{~g}$ at 0.2 $\mathrm{sec}$ and from 0.08 to more than $0.14 \mathrm{~g}$ at $0.65 \mathrm{sec}$. The predicted values within the city are in satisfactory agreement, especially at lower periods, with those determined from empirical attenuation relations (Theodulidis, 1991) which lie within 0.3 to $0.6 \mathrm{~g}$ at $0.2 \mathrm{sec}$ and 0.05 to $0.1 \mathrm{~g}$ at $0.65 \mathrm{sec}$.

We also indicatively computed average response spectra at a specific site within the city of Thessaloniki (triangle symbol in Figs. 2-4), for three representative site categories (B, C and D). The site effect was included in the average spectrum through the use of empirical amplification factors previously proposed (Margaris \& Boore 1998, Klimis et al. 1999). The resulting spectra are presented in figure 5, where dashed lines correspond to \pm 1 standard deviation. Standard deviation curves indicate the uncertainty in the average spectra due to our incapability of defining the slip dis- 
tribution, the location of the rupture initiation point and the value of parameter sfact for a hypothetical earthquake.

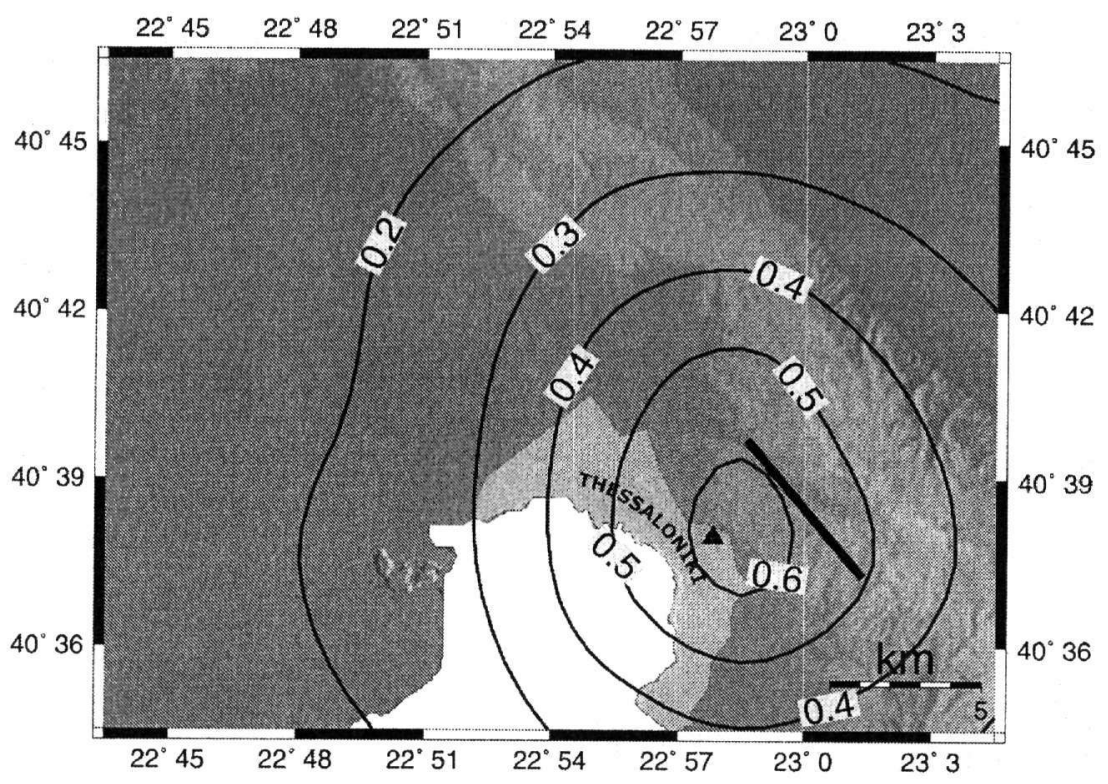

Figure 3. Average PSA map at period $T=0.2 \mathrm{sec}$ for the scenario earthquake of $M w=5.2$ on the Asvestochori fault. Values are in $\mathrm{g}$ and the contour interval is $0.1 \mathrm{~g}$. Thick black line corresponds to the projection of the upper edge of the adopted fault model to the surface.

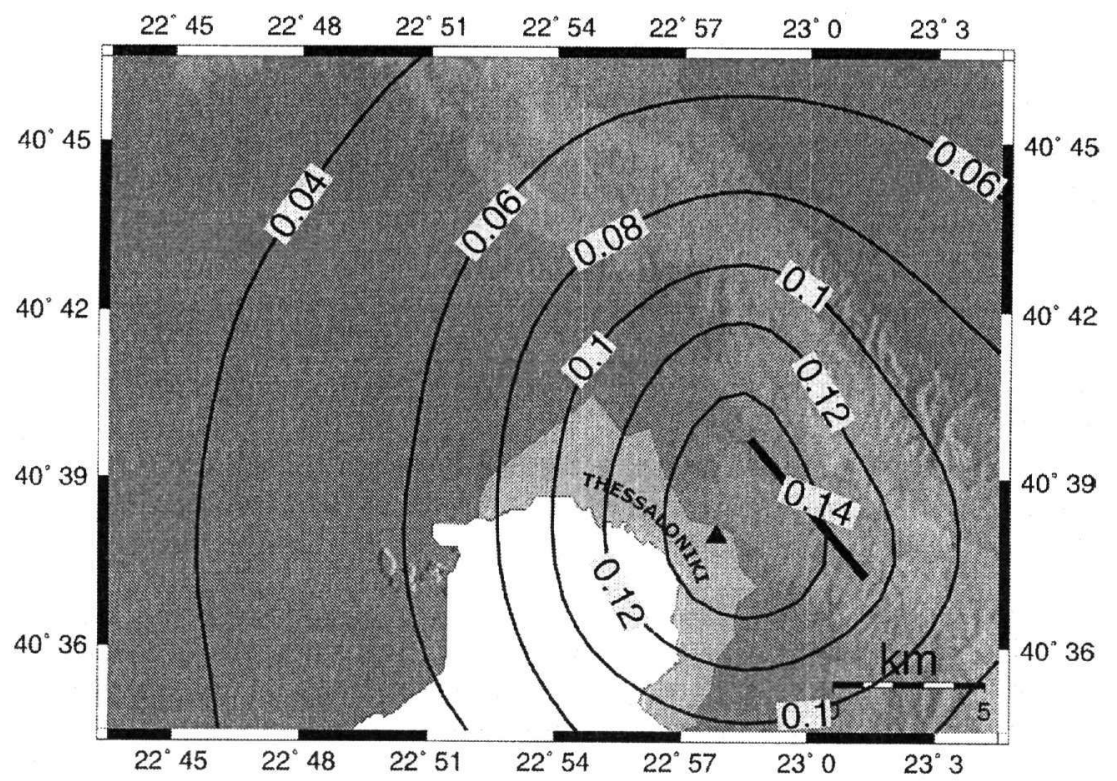

Figure 4. Average PSA map at period $T=0.65 \mathrm{sec}$ for the scenario earthquake of $\mathrm{Mw}=5.2$ on the Asvestochori fault. Values are in $\mathrm{g}$ and the contour interval is $0.1 \mathrm{~g}$. Thick black line corresponds to the projection of the upper edge of the adopted fault model to the surface. 

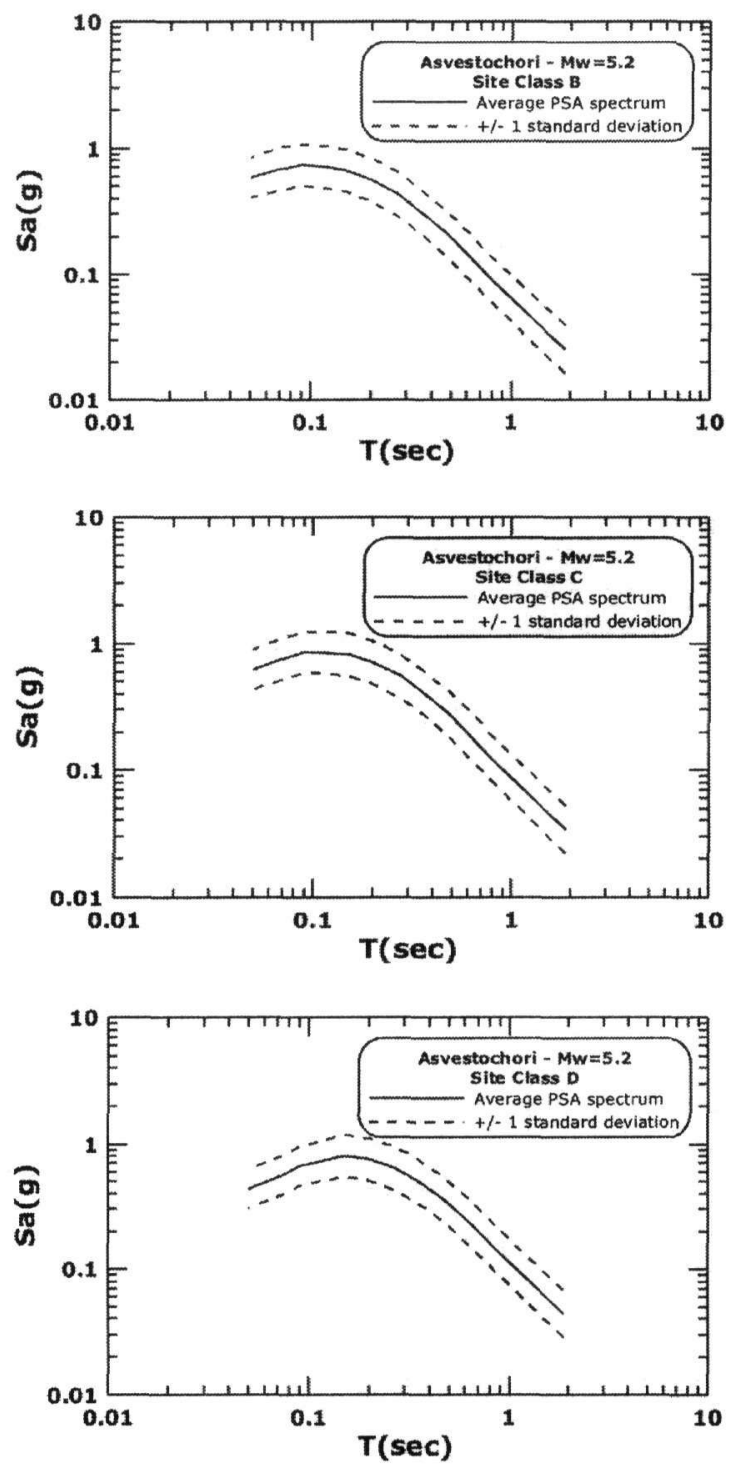

Figure 5. Average response spectra (continuous lines) and \pm 1 standard deviation curves (dashed lines) for three representative site categories ( $B, C$ and $D$ from top to bottom) at a specific site within the city of Thessaloniki, which is denoted by the triangle symbol in Figs. 2-4.

In Figure 6, we indicatively compare two site-specific estimates of average response spectra with corresponding spectra derived from empirical predictive attenuation relations (Theodulidis, 1991). Response spectra have been computed at two points, one of them located very close to the assumed seismic source $(R=1 \mathrm{~km})$ and the other one located at the western suburbs of the city $(\mathrm{R}=10 \mathrm{~km})$. The agreement between the two independently calculated sets of spectra is very satisfactory, especially in the intermediate period range $(0.1$ to $1 \mathrm{sec})$. Outside this range, the stochastically determined average spectrum deviates from the empirical one, although it remains within the \pm 1 standard deviation curves. 

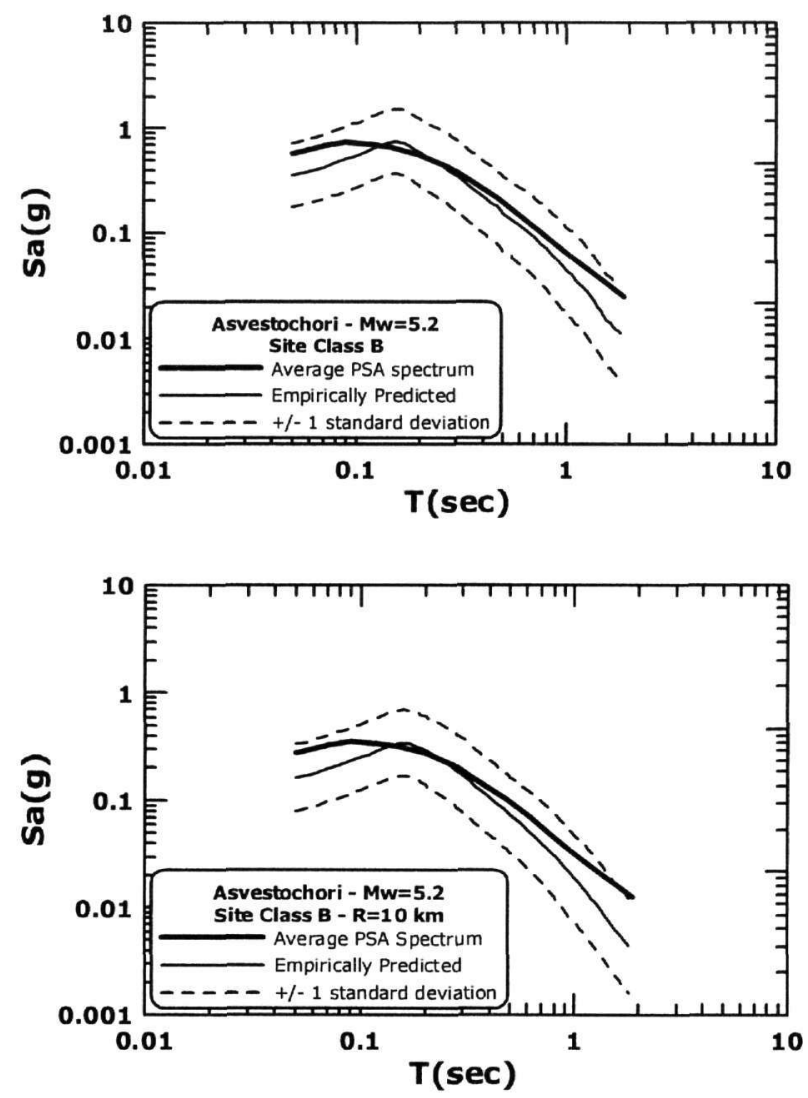

Figure 6. Comparison between average response spectra calculated using the stochastic method for finite sources (continuous thick lines) and empirically predicted spectra (continuous thin lines), at two points located at distances of $1 \mathrm{~km}$ (top) and $10 \mathrm{~km}$ (bottom). Dashed curves correspond to the \pm 1 standard deviation of the empirical spectra.

\section{CONCLUSIONS}

The stochastic method for finite faults was applied to simulate strong ground motion within the area of the Prefecture of Thessaloniki from a scenario earthquake - that is rupture of the Asvestochori fault producing a magnitude Mw 5.2 earthquake. Synthetic acceleration time histories and response spectra were computed for a large number of grid points, covering the broader area of the Prefecture of Thessaloniki. For each point we examined 5,250 rupture scenarios, which included variable slip distribution patterns, rupture initiation points and values of the sfact parameter of the stochastic method. Average PGA and PSA values at each grid point were then used to compile synthetic maps of strong ground motion parameters. By examining multiple scenarios, we were capable to produce smoothed maps and also evaluate a representative uncertainty level of the average PSA spectra, introduced by our incapability of defining certain parameters, such as the rupture initiation point, prior to the occurrence of a future earthquake.

Our results include site-specific synthetic PSA spectra for three representative soil classes ( $B, C$ and D), an average PGA map of the examined scenario earthquake at hard rock conditions, as well as average PSA maps at two reference periods $(0.2$ and $0.65 \mathrm{sec})$. Although the examined earthquake is of moderate magnitude, the resulting strong ground motions are of considerable amplitude. PGA levels within the city of Thessaloniki span the range 0.15 to $0.35 \mathrm{~g}$, whereas PSA values go up to $0.65 \mathrm{~g}$ at the period of $0.2 \mathrm{sec}$. These levels, which are in very good agreement with those 
predicted from empirical attenuation relations (Theodulidis, 1991), are expected to rise even more if coupled with site effects, a factor not taken into account in the present study.

Moderate-magnitude earthquakes can often be catastrophic, especially when occurring very close to densely populated areas e.g. urban areas (http://neic. usgs.gov/neis/eq depot). Regarding the Asvestochori fault, available geological information favors a rather short length for the entire structure. Therefore, it is not believed that the specific fault is capable of producing earthquakes of magnitude greater than 6.0 (Hatzidimitriou et al. 1990). Nevertheless, our scenario magnitude, which is based on the mapped length of the Asvestochori fault and the foci distribution of the recent 1999 earthquake áctivity, is capable of producing extended damage within the city of Thessaloniki.

The simulations performed in this study are a first-order approximation of the problem of predicting the levels of strong ground motions from future earthquakes within the Prefecture of Thessaloniki. The philosophy of the applied method is to use the simplest representations of all factors contributing to the strong motion spectrum and therefore factors such as detailed velocity models of the area or $2 \mathrm{D}$ and $3 \mathrm{D}$ site effects cannot be taken into account. The application of other strong motion simulation methods of more deterministic character and the comparison of the results of independent methodologies is one of the future targets of the SEISIMPACT-THES project.

\section{AGKNOWLEDGEMENTS}

We would like to acknowledge the partial financial support of the General Secretariat of Research and Technology (GSRT) of the Ministry of Development of Greece and the Earthquake Planning and Protection Organization (EPPO) of Greece. Thanks are also due to Igor Beresnev for kindly offering the simulation code and valuable advice.

\section{REFERENCES}

Anderson J. G., and Hough S. E. 1984. A model for the shape of the Fourier amplitude spectrum of acceieration at high frequencies. Bull. Seism. Soc. Am., 74, 1469-1993.

Benetatos Ch. \& Kiratzi A. 2004. Stochastic strong ground motion simulation of intermediate depth earthquakes: The cases of the 30 May 1990 Vrancea (Romania) and of the 22 January 2002 Karpathos island (Greece) everits. Soil Dynam. and Earthq. Eng., 24, 1-9.

Beresnev I. A. \& Atkinson G.M. 1997. Modeling finite-fault radiation from the $\omega^{n}$ spectrum. Bull. Seism. Soc. Am., 87, 67-84.

Beresnev I. A. \& Atkinson G.M. 1998. FINSIM - a FORTRAN program for simulating stochastic acceleration time histories from finite faults. Seism. Res. Lett., 69, 27-32.

Beresnev I. A, and Atkinson G. M. 1999. Generic finite-fault model for ground-motion prediction in eastern North America. Bull. Seism. Soc. Am., 89, 608-625.

Beresnev I. and Atkinson G. 2001. Subevent structuie of large earthquakes - A ground motion perspective. Geophys. Res. Lett., 23, 53-56.

Beresnev I. A. \& Atkinson G.M. 2002. Source parameters of earthquakes in eastern and western North America based on finite-fault modeling. Bull. Seism. Soc. Am., 92, 695-710.

Boore D. M. 1983. Stochastic simulation of high-frequency ground motions based on seismological models of the radiated spectra. Bull. Seism. Soc. Am., 73, 1865-1894.

Boure D. M. 2003. Simulation of ground motion using the stochastic method. Pure Appl. Geophys., 160, 635676 .

Castro R. R., Rovelli A., Cocco M., Di Boina M. \& Pacor F. 2001. Stochastic simulation of strong-motion records from the 26 September $1997\left(M_{w} 6\right)$, Umbria-Marche (Central Italy') earthquake. Bull. Seisnı. Soc. Am.. 91, 27-39.

Hanks T. C. 1979. b values and $\omega^{-\gamma}$ seismic source models: Implications for tectonic stress variations along active crustal fault zones and the estimation of high.fiequency strong ground motion. J. Geophys. Res., 84, 2235. 2242.

Hanks T. C. \& McGuire R. K. 1981. The character of high-frequency strong ground motion. Bull. Seism. Soc. Am., 71, 2071-2095.

Hartzell S., Harmsen S., Frankel A. \& Larsen S. 1999. Calculation of broadband time histories of ground motion: comparison of methods and validation using strong-ground motion from the 1994 Northridge earthquake. Bull. Seism. Scc. Am., 89, 1484-1504.

Hatzidimitriou P. M., Hatzfeld D., Skordilis E. M., Papadimitriou E. E., and Christodoulou A. A. 1990. Ssismotectonic evidence of all active normal fauit beneath Thessaloniki, Terra.Nova, 3, 648-645.

Hough S. E., Martin S., Billıam R. \& Atkinson G. M. 2003. The January 26, 2001 M7.6 Bhlij, India earthquak:e: Observed and predicted ground motions. Bull. Seism. Soc. Am., 92(6), 2061-2079. 
Kanamori H., \& Anderson D. L. 1975. Theoretical basis of some empirical relations in seismology. Bull. Seism. Soc. Am., 65, 1073-1095

Kiratzi, A. 2002. Stress tensor inversions along the westernmost North Anatolian Fault Zone and its continuation into the North Aegean Sea. Geophysical Journal International, 151, 360-376.

Klimis N. S., Margaris B. N., and Koliopoulos P. K. 1999. Site dependent amplification functions and response spectra in Greece, Journal of Earthquake Engineering, 3, 2, 237-247.

Koutoupes, S., Karantonis, G., Sotiriadis, A., Kiratzi, A., Valadaki, A., Savaidis, A., Theodulidis, N., Tziavos, I., Savaidis, P. \& I. Doukas, 2004. SEISIMPACT-THES: Design, Development and application of information system for the evaluation of seismic risk in the built environment of the prefecture of Thessaloniki. Bull. of the Geol. Soc. of Greece, XXXVI (this volume), in Greek.

Margaris B. N. \& Papazachos B. C. 1994. Seismic Hazard Simulation of Strong Motion Based on Source Parameters in the Area of Greece. Proc. XXIV Gen. Ass. ESC, Sept. 19-24, 1994, Athens, III, 1389-1397.

Margaris B. N. \& Hatzidimitirou P. 1997. Source parameters of the Arnea earthquake, $M_{S}=5.8$, based on stochastic simulation method, Proc. $3^{d}$ Pan. Conf. Geotech. Eng., March 20-22, Patra, 503-510.

Margaris B. N. \& Boore D. M. 1998. Determination of $\Delta \sigma$ and $K_{0}$ from response spectra of large earthquakes in Greece. Bull. Seism. Soc. Am., 88, 170-182.

McGuire R. K. \& Hanks T. C. 1980. rms accelerations and spectral amplitudes of strong ground motion during the San Fernando, California, earthquake. Bull. Seism. Soc. Am., 70, 1907-1919.

Papastamatiou D., Margaris B. \& Theodoulidis N. 1993. Estimation of the parameters controlling strong ground motion from shallow earthquakes in Greece. Proc. $2^{\text {nd }}$ Hell. Geoph. Congr., May 5-7, 1993, Florina, I, $192-$ 201.

Papazachos B. C., \& Papazachou C. 2003. The earthquakes of Greece. Ziti Publ. Co., Thessaloniki, Greece, 286 pp (in Greek).

Papazachos C., Soupios P., Savvaidis A., and Roumelioti Z. 2000. Identification of small-scale active faults near metropolitan areas: An example from the Asvestochori fault near Thessaloniki. XXVII General Assembly of the European Seismological Commission (ESC), September 2000, Lisbon, Portugal.

Roumelioti Z. \& Kiratzi A. 2002. Stochastic simulation of strong-motion records from the 15 April 1979 (M 7.1 ) Montenegro earthquake. Bull. Seism. Soc. Am., 92, 1095-1101.

Roumelioti Z., Kiratzi A., Theodoulidis N. \& Papaioannou Ch. 2000. A comparative study of a stochastic and deterministic simulation of strong ground motion applied to the Kozani-Grevena (NW Greece) 1995 sequence. Annali di Geofisica, 43, 951-966.

Roumelioti Z., Kiratzi A., Theodoulidis N., Kalogeras I. \& G. Stavrakakis 2003. Rupture directivity during the September 7, $1999\left(M_{w}\right.$ 5.9) Athens (Greece) earthquake obtained from strong-motion records. Pure and Appl. Geophys., 160(12), 2301-2318.

Roumelioti Z., Kiratzi A. \& N. Theodoulidis 2004. Stochastic strong ground motion simulation of the 7 September 1999 Athens (Greece) earthquake. Bull. Seism. Soc. Am, 94(3), 1036 - 1052.

Savvaidis P., Doukas I., Hatzigogos Th., Tziavos I.N., Kiratzi A., Roumelioti Z., Savvaidis A., Theodulidis N., Drakatos G., Koutoupes S., Karantonis G., \& A. Sotiriadis, 2004. SEISIMPACT-THES: A system for the evaluation of seismic impact in the built environment of the prefecture of Thessaloniki, Bull. of the Geol. Soc. Greece., XXXVI (this volume).

Singh S. K., Bansal B. K., Bhattacharya S. N., Pacheco J. F., Dattatrayam R. S., Ordaz M., Suresh G., Kamal \& Hough S. E. 2003. Estimation of ground motion for Bhuj (26 January, 2001; $M_{w}=7.6$ ) and for future earthquakes in India. Bull. Seism. Soc. Am., 93(1), 353-370.

Theodulidis, N. P. 1991. Contribution to strong ground motion study in Greece, PhD Thesis, Aristotle University of Thessaloniki, $500 \mathrm{pp}$ (in Greek).

Tranos M. D., Papadimitriou E. P., \& A. Kilias, 2003. Thessaloniki-Gerakarou Fault Zone (TGFZ): the western extension of the 1978 Thessaloniki earthquake fault (Northern Greece) and seismic hazard assessment. J. Struct. Geology, 25(12), 2109-2123. 